\title{
Synchronous Oscillatory Activity in Immature Cortical Network Is Driven by GABAergic Preplate Neurons
}

\author{
Thomas Voigt, Thoralf Opitz, and Ana D. de Lima \\ Otto-von-Guericke Universität, Medizinische Fakultät, Institut für Physiologie, 39120 Magdeburg, Germany
}

\begin{abstract}
Neurons dissociated from embryonic cerebral rat cortex form a differentiated network of synaptic connections and develop synchronous oscillatory network activity with the beginning of the second week in culture. During an initial phase lasting 3-4 d, synchronous calcium transients can be blocked completely by either CNQX or bicuculline, showing that both glutamatergic and GABAergic neurons are required for the generation of this form of activity. By manipulating dissociation and growth conditions, cultures containing different populations of GABAergic neurons were obtained. These cultures revealed that a distinct population of large GABAergic neurons is a key element in the generation of synchronous oscillatory network activity. A minimal number of two large GABAergic neurons per square millimeter are required for the occurrence of synchronous activity. Changes in the density of all other types of GABAergic or non-GABAergic neurons has no influence on the
\end{abstract}

The spontaneous occurrence of rhythmic synchronous activity is thought to provide immature brain structures with the appropriate activity patterns required for synaptic maturation. This form of synchronous neuronal activity has been described in recent years in a variety of CNS structures (for review, see Shatz, 1990; Katz and Shatz, 1996; O'Donovan, 1999). These population events occur rhythmically at a low frequency of approximately one event per minute. In the mammalian retina, for example (Galli and Maffei, 1988; Meister et al., 1991), waves of synchronized activity are generated in the inner plexiform layer well before the photoreceptors are born (Wong et al., 1995) but just in time to provide the retinal axons with the appropriate activity patterns needed for the activity-dependent refinement of their arbors within the target areas (Sretavan et al., 1988; Penn et al., 1998). Similarly, in rat hippocampus (Ben-Ari et al., 1989; Garaschuk et al., 1998) and cerebral cortex (Garaschuk et al., 2000; Peinado, 2000), massive population discharges are fully developed at birth, when most of the synaptic connections are established (Kristt, 1978; Juraska and Fifkova, 1979). A key element in the generation of the synchronous population activity is the initially excitatory nature of neurotransmitters that have inhibitory function in the mature network (Ben-Ari et al., 1989;

\footnotetext{
Received Jan. 26, 2001; revised Aug. 21, 2001; accepted Aug. 28, 2001.

This work was supported by the Deutsche Forschungsgemeinschaft. We thank Birgit Adam for technical assistance, Thomas Dresbach, Hans-Christian Pape, and Patric K. Stanton for comments on this manuscript, and André M. Goffinet and Clermont Beaulieu for the generous gift of antibodies.

Correspondence should be addressed to Dr. Thomas Voigt, Otto-von-GuerickeUniversität Magdeburg, Medizinische Fakultät, Institut für Physiologie, Leipziger Strasse 44, D-39120 Magdeburg, Germany. E-mail: Thomas.Voigt@Medizin.UniMagdeburg.de.

Copyright (C) 2001 Society for Neuroscience $\quad 0270-6474 / 01 / 218895-11 \$ 15.00 / 0$
}

synchronous activity. Electron microscopic analysis shows that the large GABAergic neurons form an interconnected network. Exceptionally high somatodendritic innervation and extended axonal arborization enable these neurons to collect electric network activity and to distribute it effectively throughout the neuronal network. Additional experiments indicated that most neurons developing in culture to large GABAergic neurons are derived from the primordial plexiform layer and reside in the subplate at the time of birth. We suggest that they function as an integrating element that synchronizes neuronal activity during early cortical development by collecting incoming extrinsic and intrinsic signals and distributing them effectively throughout the developing cortical plate.

Key words: development; cerebral cortex; calcium; synchronous activity; GABA; subplate

O'Donovan, 1999). With the consolidation of the synaptic connections, GABA gains gradually its inhibitory capacity, and synchronous activity wears off, releasing the developing system into the functional state required for future function (Wong et al., 1993; Isaac et al., 1997; Garaschuk et al., 1998, 2000).

Here we identify a distinct type of GABAergic neuron as a key element for the formation of synchronous neuronal activity in the developing cerebral cortex. By systematically altering the content of GABAergic neurons in neuronal networks formed by embryonic cortical neurons, we show that networks lacking large GABAergic neurons display a significant delay in the development of synchronous activity. Birth-dating experiments combined with GABA immunocytochemistry in vitro and in the intact brain indicate that large GABAergic neurons are components of the subplate at the time of birth.

\section{MATERIALS AND METHODS}

Cell culture technique. Neuronal cultures were prepared from cerebral cortices of embryonic Sprague Dawley rats at embryonic day 15 (E15)E16 (day after insemination was E1). The cells were taken from the dorsolateral parts of the telencephalic vesicles (excluding hippocampal and basal telencephalic anlagen), dissociated with trypsin-EDTA, and cultivated on poly-D-lysine-coated coverslips in serum-free medium in the presence of a glial feeding layer (de Lima and Voigt, 1999). Cultures with different contents of GABAergic neurons were obtained by varying the time point at which neuronal proliferation was stopped $[2$ or $6 \mathrm{~d}$ in vitro (DIV)], the plating density $\left(100-300 \mathrm{cells} / \mathrm{mm}^{2}\right)$, or the age of the embryos (E15-E16). Large GABAergic neurons are postmitotic at the time of plating and do not divide in culture, whereas small GABAergic neurons are not yet born at this point. They are generated in vitro during the second half of the first culturing week (de Lima and Voigt, 1997, 1999). Thus termination of mitotic activity by application of cytosine arabinoside (AraC; $5 \mu \mathrm{M}$ for $24 \mathrm{hr}$, followed by one-third change of medium) at 2 DIV resulted in cultures lacking small GABAergic neu- 
rons. Later termination of mitotic activity (6 DIV) allowed the generation of small GABAergic neurons, resulting in cultures with large and small GABAergic neurons (de Lima and Voigt, 1997, 1999). Because of the low incidence of large GABAergic neurons in cell suspensions dissociated from E15-E16 embryos, a low plating density resulted in cultures with the lowest density of large GABAergic neurons. In combination with early AraC application (2DIV), cultures were obtained that in extreme cases had several square millimeters of the neuronal network devoid of any GABAergic nerve cell. Late AraC application in these low-density plated cultures allowed the generation of small GABAergic neurons. Cortical cultures from younger embryos (E15) tended to have a lower density of large GABA neurons. Examples of all four culture types, however, were obtained from both E15 and E16 embryos with no apparent difference in their morphological or physiological development. The nature of the non-GABAergic cells was monitored by microtubule-associated protein 2 (MAP-2) and glial fibrillary acidic protein immunocytochemistry. Correlation between synchronous neuronal activity and local cell density was determined by cell counts at the sites of calcium imaging. Depending on the local cell density, sampling areas varied between 0.02 and $1,56 \mathrm{~mm}^{2}$ around the centered 0.14 $\mathrm{mm}^{2}$ field recorded by the camera.

To raise cultures with blocked glutamatergic transmission, a mixture of the glutamate antagonists D-2-amino-5-phosphonopentanoic acid (AP-V; $50 \mu \mathrm{M}$ ) and 6-cyano-7-nitroquinoxaline-2,3-dione disodium (CNQX; 10 $\mu \mathrm{M}$; Tocris Cookson; purchased from Biotrend, Cologne, Germany) was added to the culture medium at 2, 6, and 10 DIV.

Immunocytochemical staining. For immunocytochemical staining, the following antibodies were used: polyclonal rabbit anti-GABA (C. Beaulieu, University of Montréal, Montréal, Québec, Canada; 1:20,000), monoclonal mouse anti-synaptophysin (Roche Molecular Biochemicals, Mannheim, Germany; 1:10), monoclonal mouse anti-5-bromo-2'deoxyuridine (BrdU) antibodies (Roche Molecular Biochemicals;1:50), monoclonal mouse anti-reelin G10 antibodies (A. Goffinet, University of Namur; 1:2000,), and monoclonal anti-mouse p75 antibody (Chemicon, Temecula, CA; 1:10,000). Single and double immunolabeling were used following standard procedures (de Lima and Voigt, 1997, 1999; de Lima et al., 1997; Voigt et al., 1997). First antibodies were detected either by peroxidase-antiperoxidase techniques (Sternberger Meyer, Baltimore, $\mathrm{MD})$ or with Cy2 and Cy3 immunofluorescence antibodies (1:400; Jackson ImmunoResearch, West Grove, PA). The time point of the final mitosis of large GABAergic neurons was determined by intraperitoneal injections of $50 \mathrm{mg} / \mathrm{kg}$ body weight BrdU (Serva, Heidelberg, Germany; and Roche Molecular Biochemicals) to the pregnant dams every $3 \mathrm{hr}$ for a total of five injections per time point at E12, E13, E14, E15, or E16 (E16 had only three injections; Takahashi et al., 1992). Cell cultures were prepared from the embryos at E16, and cells were cultivated for $2 \mathrm{~d}$ under standard conditions. The fixation at 2DIV excluded the presence of the later-born small GABAergic cells. For in vivo localization of large GABAergic neurons, intraperitoneal injections of BrdU were given to pregnant dams at E12 or in another set of experiments at E14 following the same regimen as above. A total of three pups per time point were fixed by perfusion with a mixture of $4 \%$ paraformaldehyde and $0.001 \%$ glutaraldehyde at the day of birth [postnatal day $0(\mathrm{P} 0)$ ], and GABA and BrdU immunocytochemistry was performed on free-floating sections. For quantitative analysis, 100 randomly chosen GABA neurons were analyzed for BrdU double labeling in each of the following layers: ventricular zone, intermediate zone, subplate, lower cortical plate, upper cortical plate, and marginal zone.

Electron microscopic analysis. For electron microscopy, cultures that received AraC at 2 DIV were immunolabeled for GABA with a few modifications of the protocol for light microscopy. Cultures were postfixed in $1 \%$ osmium tetroxide for $30 \mathrm{~min}$, dehydrated in an ascending series of ethanol, block-stained with $1 \%$ uranyl acetate in $70 \%$ ethanol during the dehydration procedure, infiltrated, and embedded with Durcupan (Fluka, Buchs, Switzerland). Glas coverslips were separated from the Durcupan block by temperature shock. Pieces of the embedded cultures were then cut and glued onto a blank block, and the region of interest was closely trimmed. Ultrathin sections were cut and mounted onto single-slot grids, counterstained with uranyl acetate and lead citrate, and examined with a Zeiss (Oberkochen, Germany) 901 electron microscope.

$\mathrm{Ca}^{2+}$ imaging technique. For recording intracellular calcium concentration $\left(\left[\mathrm{Ca}^{2+}\right]_{\mathrm{i}}\right)$ changes in neuronal networks, cell cultures were incubated in $5 \mu \mathrm{M}$ fluo-3 pentacetoxy-methylester (Molecular Probes; purchased from MoBiTec, Goettingen, Germany) for $1 \mathrm{hr}$, followed by several washes with HEPES-buffered Ringer's solution (in mM: 140
$\mathrm{NaCl}, 5 \mathrm{KCl}, 1.5 \mathrm{CaCl}_{2}, 0.75 \mathrm{MgCl}_{2}, 1.25 \mathrm{NaH}_{2} \mathrm{PO}_{4}, 20$ D-glucose, and 15 HEPES-NaOH, pH 7.4). Sequences of frames were recorded at $1-10 \mathrm{~Hz}$ from randomly chosen fields on an inverted microscope equipped with a cooled charge-coupled device camera (Princeton Instruments). Images were processed with MetaMorph software, version 3.5 (Universal Imaging Corp., West Chester, PA). A change in $\left[\mathrm{Ca}^{2+}\right]_{i}$ was considered significant when the absolute difference of gray values exceeded five times the SD of background noise measured in cell-free areas.

Patch-clamp-recordings. For patch-clamp-recording, the feeder glia surrounding the neuronal culture was wiped off, and an acrylic ring was fixed to the culture dish with silicon grease, resulting in a chamber with a volume of $1-1.5 \mathrm{ml}$. This chamber was mounted on the stage of the inverted microscope and continuously superfused with Ringer's solution (in mM: $145 \mathrm{NaCl}, 2.5 \mathrm{KCl}, 2 \mathrm{CaCl}_{2}, 1 \mathrm{MgCl}_{2}, 10 \mathrm{HEPES}, \mathrm{pH} 7.4$ ) at $1-2$ $\mathrm{ml} / \mathrm{min}$. For some experiments, tetrodotoxin (TTX; $500 \mathrm{nM}), \mathrm{LaCl}_{3}(50$ $\mu \mathrm{M})$, and CNQX $(10 \mu \mathrm{M})$ were added to inhibit voltage- and glutamateactivated conductances. Electrophysiological recordings were performed at room temperature using an Axoclamp 2B amplifier and pClamp 8 software (Axon Instruments). We used the perforated patch method with gramicidin as the pore-forming agent, because this prevents disturbance of intracellular $\left[\mathrm{Cl}^{-}\right]$(Kyrozis and Reichling, 1995). Only the very tip of the recording electrode $(5-7 \mathrm{M} \Omega$ ) was filled with gramicidin-free solution (in mM: $120 \mathrm{KCl}, 1 \mathrm{CaCl}_{2}, 11$ EGTA, $10 \mathrm{HEPES}, \mathrm{pH}$ 7.2). The electrode was then back-filled with the same solution containing $50 \mu \mathrm{g} / \mathrm{ml}$ gramicidin (Sigma, Deisenhofen, Germany) that was added from a $50 \mathrm{mg} / \mathrm{ml}$ DMSO stock solution. After gigaseal formation, hyperpolarizing voltage pulses were applied in continuous voltage-clamp mode until stable series resistance was reached (typically $30-50 \mathrm{M} \Omega$ within $10-20 \mathrm{~min}$ ). To determine the reversal potential of $\mathrm{GABA}_{\mathrm{A}}$ receptor-mediated current, we locally applied $30 \mu \mathrm{M}$ muscimol (Sigma-Aldrich, Taufkirchen, Germany) through a gravity-fed system (tip diameter, $30 \mu \mathrm{m} ; \sim 300 \mu \mathrm{m}$ distance from patched neuron). A voltage ramp $(20$ to $-100 \mathrm{mV}$ within $800 \mathrm{msec}$ ) was applied when the current had reached steady state. After leak subtraction, $I-V$ plots were constructed, and reversal potential was computed by linear regression. All experimental procedures were approved by local government authorities.

\section{RESULTS}

\section{Development of synchronous network activity}

Synchronous changes of $\left[\mathrm{Ca}^{2+}\right]_{i}$ develop in neuronal cultures taken from embryonic rat cerebral cortex with a very high reliability around the beginning of the second week in culture (Fig. $1 A, B)$. These population events occur spontaneously at a low frequency of approximately one per minute and are expressed initially only by a fraction of the neurons. With further maturation, however, basically all nerve cells become integrated into the network and participate in synchronous activity (Voigt et al., 1997). During the initial period of 3-4 d (8-12 DIV), the synchronous calcium transients are dependent not only on glutamatergic transmission but also on GABA. Application of the AMPA receptor antagonist $C N Q X$ or the $\mathrm{GABA}_{\mathrm{A}}$ receptor antagonists bicuculline and picrotoxin completely and reversibly blocks the synchronous rise of $\left[\mathrm{Ca}^{2+}\right]_{\mathrm{i}}$ within a neuronal network (Fig. $1 C, D)$. After this initial period, bicuculline application no longer prevents the occurrence of synchronous changes in $\left[\mathrm{Ca}^{2+}\right]_{i}$ but significantly reduces the frequency of the synchronous events (data not shown). Both the complete block of synchronous activity between 8 and 12 DIV and the later reduction in frequency are in agreement with a depolarizing effect of GABA on young cortical neurons (Owens et al., 1996, 1999). Indeed, in 8-12 DIV cultured cortical neurons, we found the reversal potential of currents induced by the $\mathrm{GABA}_{\mathrm{A}}$ receptor agonist muscimol to be $-44.6 \pm 1.4 \mathrm{mV}$, which is $\sim 10 \mathrm{mV}$ more positive than the measured resting membrane potential in the same cells $(-54.8 \pm$ $1.1 \mathrm{mV} ; n=13)$. Application of $30 \mu \mathrm{M}$ muscimol in the presence of $10 \mu \mathrm{M} C N Q X$ and $50 \mu \mathrm{M} \mathrm{AP-V}$ was able to trigger a calcium 

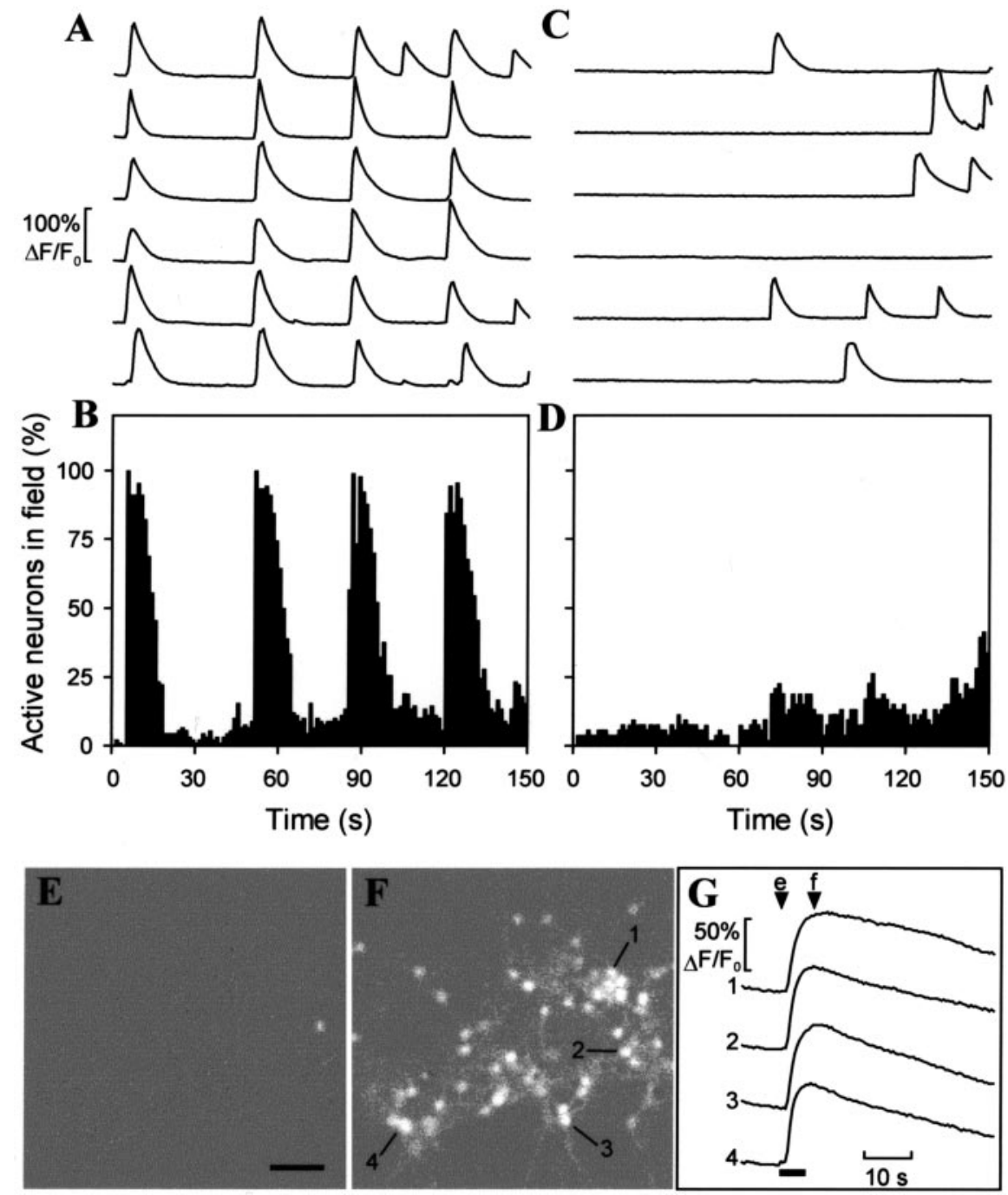

Figure 1. Synchronous $\left[\mathrm{Ca}^{2+}\right]_{\mathrm{i}}$ oscillations in cultured neurons from immature cerebral cortex. $A$, Fluorometric $\mathrm{Ca}^{2+}$ recordings of 6 representative neurons of 99 in a field of $380 \times 380 \mu \mathrm{m}^{2}$. Fluorescence data are expressed as $\Delta F / F_{0}$ (backgroundcorrected increase in fluorescence divided by the resting fluorescence). $B$, Activity histogram of all neurons in this field. Each bar represents the number of neurons that changed their $\left[\mathrm{Ca}^{2+}\right]_{\mathrm{i}}$ significantly within $1 \mathrm{sec}$. An increase or decrease of greater than five times the SD of background fluorescence was considered significant. $C$, Fluorometric $\mathrm{Ca}^{2+}$ recordings of the same six neurons as in $A$ after application of $20 \mu \mathrm{M}$ bicuculline. $D$, Activity histogram of all 99 neurons in the recorded field after application of $20 \mu \mathrm{M}$ bicuculline. $E, F$, Imaging of $\left[\mathrm{Ca}^{2+}\right]_{\mathrm{i}}$ in a field containing 49 neurons before $(E)$ and during $(F)$ application of $30 \mu \mathrm{M}$ muscimol in the presence of $10 \mu \mathrm{M}$ CNQX and $50 \mu \mathrm{M}$ AP-V. $G$, Fluorometric $\mathrm{Ca}^{2+}$ recordings of the four representative neurons indicated in $F$ (1-4). Arrowheads $e$ and $f$ indicate the time points at which the photographs in $E$ and $F$ were taken. The bar indicates the time of muscimol application. Scale bar: $E, F, 50 \mu \mathrm{m}$. signal in all nerve cells in the fields under investigation $(n=7)$, indicating that at this age (8-12 DIV) all neurons are sensitive to GABA (Fig. 1E,F).

\section{Occurrence of synchronous oscillatory activity in culture is dependent on the presence of a distinct type of GABAergic neurons}

Neuronal cultures from embryonic rat cerebral cortex contain two groups of GABAergic neurons that can easily be distinguished by their morphology (Fig. 2). One type of GABAergic neurons has a large soma (mean soma area at $10 \mathrm{DIV}, 209.7 \pm 5.6 \mu \mathrm{m}^{2} ; n=$ $30)$ and a prominent stellate dendritic tree, and it forms longrange axonal connections (Fig. $2 A, C$ ). These neurons do not divide in culture, and they account for $<4 \%$ of all cultured neurons (de Lima and Voigt, 1997). The other type of GABAergic neurons has a much smaller cell body (mean soma area at 10 DIV, $54.8 \pm 1.8 \mu \mathrm{m}^{2} ; n=30$ ), fine and predominantly bipolar or fusiform dendrites, and a thin, short axon (Fig. 2B,C). These neurons are generated in culture during the second half of the first week, and they outnumber the large GABAergic neurons at the end of the second week in culture (de Lima and Voigt, 1997, 1999). To investigate the contribution of these different GABAergic cell types to the formation of synchronous activity within the developing neuronal network, we generated cultures with different contents of GABAergic neurons. The systematic alteration of the plating density and the time at which mitotic activity was terminated resulted in neuronal networks that contained only large GABAergic neurons (Fig. 2A), only small GABAergic neurons (Fig. $2 B$ ), both types of GABAergic neurons (Fig. $2 C$ ), or no GABAergic neurons (Fig. 2D). Under all these culture conditions, richly interconnected neuronal networks developed with no apparent alterations in the neuronal morphology (as verified with anti-GABA and anti-microtubule-associated protein 2 immunocytochemistry) or in cell survival (as verified with propidium iodide and by cell density counts). Changes in the neuronal $\left[\mathrm{Ca}^{2+}\right]_{\mathrm{i}}$ were recorded in randomly chosen fields. Under all conditions, spontaneous changes in the $\left[\mathrm{Ca}^{2+}\right]_{\mathrm{i}}$ were observed. After anti-GABA immunocytochemistry, the total cell density and the density of small and large GABAergic neurons were determined at each recording site. Figure 3 shows the correlation between the local cell densities and the maximal number of neurons participating in synchronous activity during the recording period under the four culturing conditions. The analysis of the entire data set containing fields of all four types of networks showed that the occurrence of synchronous changes in $\left[\mathrm{Ca}^{2+}\right]_{i}$ was well correlated with the local density of the large GABAergic neurons. A total of 52 fields with two or more large GABAergic neurons $/ \mathrm{mm}^{2}$ expressed synchronous activity, whereas 43 of 47 recorded fields that contained fewer than two large GABAergic 
Figure 2. Neuronal cultures with different contents of GABAergic neurons. $A$, A culture with only large GABAergic cells was achieved by inhibiting mitosis at the second DIV. B, A network with only small GABAergic neurons developed when cells were plated with lower density and mitosis was stopped only at the sixth DIV. $C$, Mitotic inhibition at the sixth DIV in cultures with normal plating density allowed appearance of both large and small GABAergic neurons. $D$, Early inhibition of mitosis at the second DIV in lowdensity plated cultures yielded networks with no GABAergic cells at all. GABAergic neurons were made visible by antiGABA immunocytochemistry and peroxidase-antiperoxidase labeling. Scale bar, $30 \mu \mathrm{m}$.
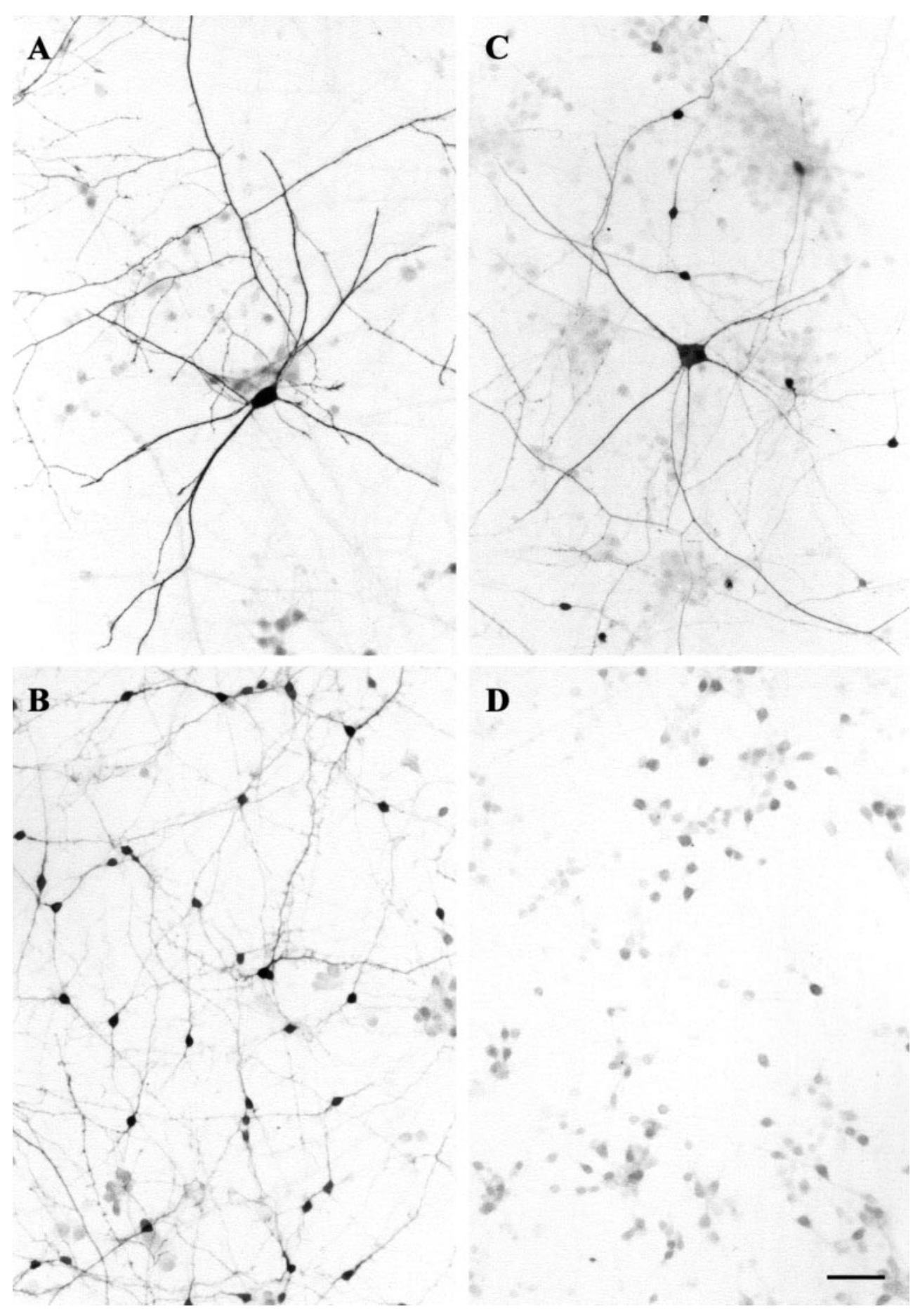

D
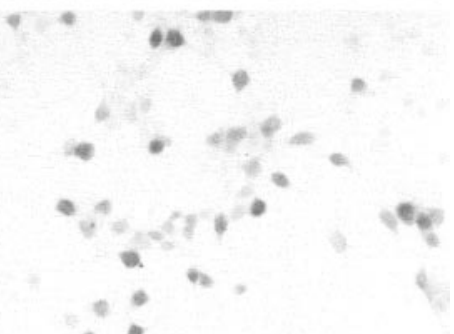

neurons $/ \mathrm{mm}^{2}$ expressed no synchronous activity (data from 21 cultures obtained in six experiments; Fig. $3 A$ ). Analyzing those cultures that contained only one population of GABAergic neurons confirmed this finding. In 35 of 37 neuronal networks that contained only small and no large GABAergic neurons, no synchronous activity was observed (Fig. 3B). The local density of small GABAergic neurons ranged in these experiments from 0 to 215 neurons $/ \mathrm{mm}^{2}$. In cultures with only large and no small GABAergic neurons (Fig. $3 C$ ), synchronous activity was observed in all of the 11 recorded fields with a local density of two or more large GABA neurons $/ \mathrm{mm}^{2}$. All 17 remaining fields with densities of fewer than two large GABAergic neurons $/ \mathrm{mm}^{2}$, however,

expressed only random but no synchronous activity. An additional increase in the density of large GABA neurons had no effect on the frequency of events (data not shown) or on the number of neurons participating in these events (Fig. $3 A, C$ ). The fit of a nonlinear regression to the data resulted in a step function when the density of large GABA cells was plotted against the number of synchronously active cells (Fig. $3 A, C$ ). The occurrence of synchronous activity was independent of the total local cell density (Fig. 3D). From these experiments we conclude that the large GABAergic neurons, although accounting for $<4 \%$ of all neurons, are crucial for the generation of synchronous activity during the early period of network formation. 

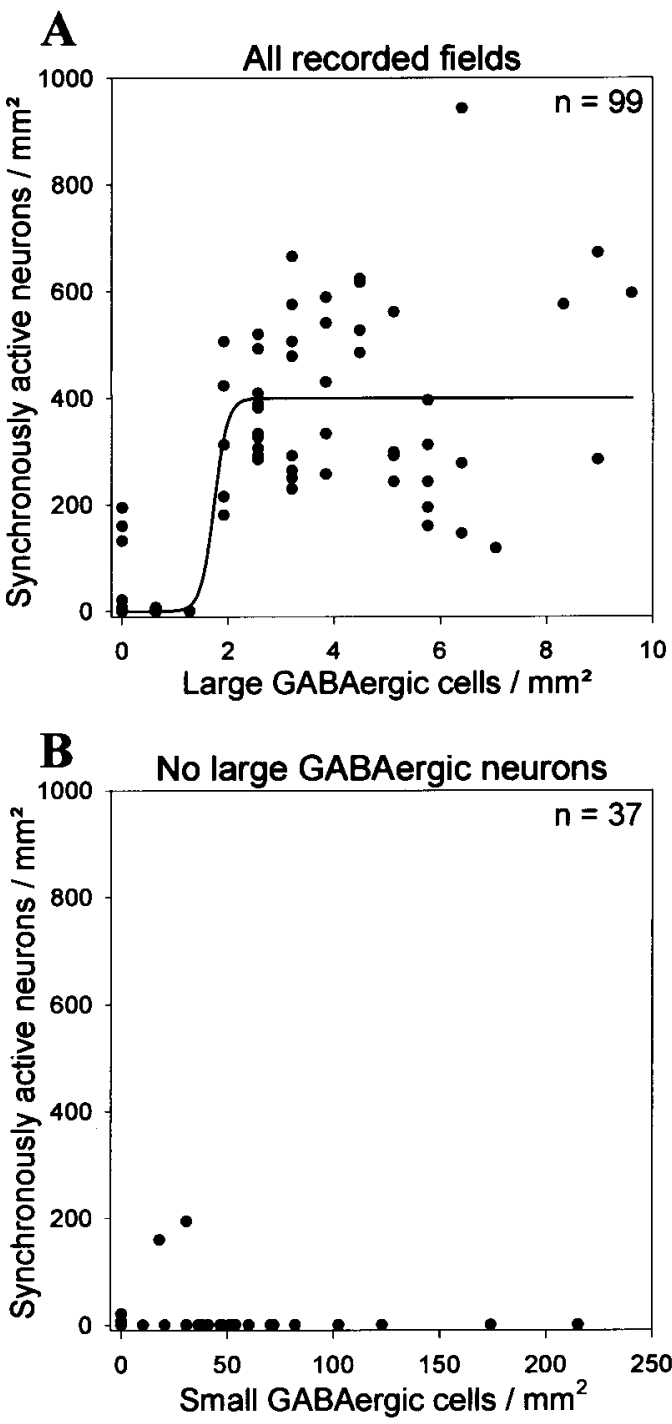
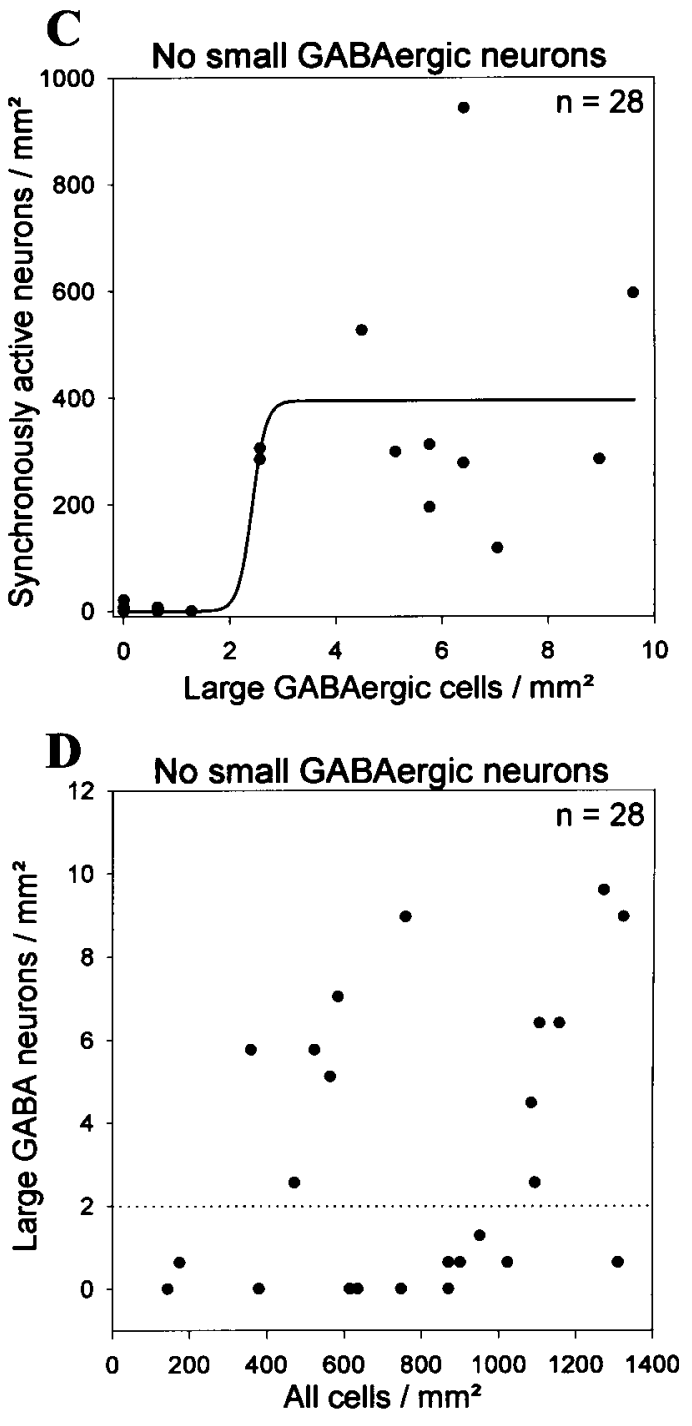

Figure 3. Occurrence of synchronous $\left[\mathrm{Ca}^{2+}\right]_{i}$ oscillations correlates with the presence of large GABAergic neurons. $A$, Density of large GABAergic neurons plotted against the number of neurons taking part in synchronous $\left[\mathrm{Ca}^{2+}\right]_{i}$ oscillations in all recorded fields no matter whether small GABAergic neurons were present. The solid line represents a nonlinear regression curve following a Boltzmann sigmoid equation. $B$, Plot of density of small GABAergic neurons against the number of neurons taking part in synchronous $\left[\mathrm{Ca}^{2+}\right]_{\mathrm{i}}$ oscillations in cultures containing no large GABAergic cells. $C$, Density of large GABAergic neurons plotted against the number of neurons taking part in synchronous $\left[\mathrm{Ca}^{2+}\right]_{\mathrm{i}}$ oscillations in cultures containing no small GABAergic cells. As in $A$, the solid line represents a nonlinear regression curve following a Boltzmann sigmoid equation. $D$, Density of all cells plotted against the number of large GABAergic neurons for the fields shown in $A$. The dashed line separates fields where synchronous $\left[\mathrm{Ca}^{2+}\right]_{\mathrm{i}}$ oscillations were present (points in top part) and absent ( points in bottom part).

\section{Large GABAergic neurons form an interconnected network and receive strong synaptic inputs}

Being a key element in the generation of synchronous activity, these neurons express some unique morphological features that distinguish them from all other nerve cells in cultures. In double-staining experiments with antibodies against synaptophysin and GABA, large GABAergic neurons stand out by an extreme high density of intensely stained synapses contacting their soma and dendrites (Fig. 4A, closed arrows) against a sparsely labeled background of more or less evenly distributed synaptic buttons (Fig. 4A, open arrow). The synaptic density is so strong that the neuronal profiles of these cells can be identified solely by the accumulation of stained synapses (de Lima et al., 1997). From 100 cell profiles identified on the basis of their high synaptic density, all were GABAergic, indicating that no other cultured neurons get such an exuberant input. Ultrastructural analysis of cultures stained immunocytochemically for GABA showed that the cell bodies and dendrites of large GABAergic neurons were studded with GABAergic and non-GABAergic synaptic boutons (Fig. $4 B-D, F$ ). The axons of these cells contact somata and dendrites of non-GABAergic and GABAergic neurons (Fig. 4E,F). Taken together, the light and electron microscopic analyses indicate that each large
GABA neuron receives exceptionally high somatic and dendritic innervation that is distributed to other large GABAergic neurons and to non-GABAergic neurons (Figs. 4, 5).

In addition to the strong GABAergic and non-GABAergic synaptic inputs, these neurons have additional morphological features that make them ideally suited to distribute neuronal activity effectively among the members of the developing neuronal network. Already at $8 \mathrm{DIV}$, the earliest time point when synchronous activity can reliably be observed in cultured cortical networks, large GABAergic neurons show extended axonal arborization that covers a surface of $>0.5 \mathrm{~mm}^{2}$ (mean at $8 \mathrm{DIV}$, $0.53 \mathrm{~mm}^{2} ; n=6$; mean at 12 DIV, $0.61 \mathrm{~mm}^{2} ; n=4$; Fig. 5). Multiplying the mean surface covered by the axons of these neurons with the density required for the occurrence of synchronous network activity results in a coverage factor. At 8 DIV, the coverage factor was slightly larger than 1 ; i.e., with a size of 0.53 $\mathrm{mm}^{2}$ and a density of two neurons $/ \mathrm{mm}^{2}$, these cells can theoretically form a continuous interconnected GABAergic network. The ultrastructural identification of GABAergic synapses onto large GABAergic neurons in cultures lacking small GABAergic neurons (Fig. $4 F$ ) supports this view and indicates that the formation of an interconnected network of large GABAergic neu- 
Figure 4. Exceptionally high density of synapses onto large GABAergic neurons. $A$, Light microscopic photograph of a cultured neuron double-immunolabeled for GABA (light gray) and synaptophysin (dark gray). B, Electron microscopic photograph of a dendritic segment of a large GABAergic neuron densely covered with presynaptic boutons. $C, D$, Asymmetric (supposedly glutamatergic) synapses onto an immunolabeled GABAergic cell soma $(C)$ and dendrite $(D) . E, F$, Example of a GABAergic synapse onto a nonGABAergic $(E)$ and onto a GABAergic $(F)$ dendritic profile. Arrows in $A-F$ point to synaptic contacts. Scale bar: $A, 20 \mu \mathrm{m}$; $B, 0.6 \mu \mathrm{m} ; C-E, 0.4 \mu \mathrm{m} ; \mathrm{F}, 1.4 \mu \mathrm{m}$.

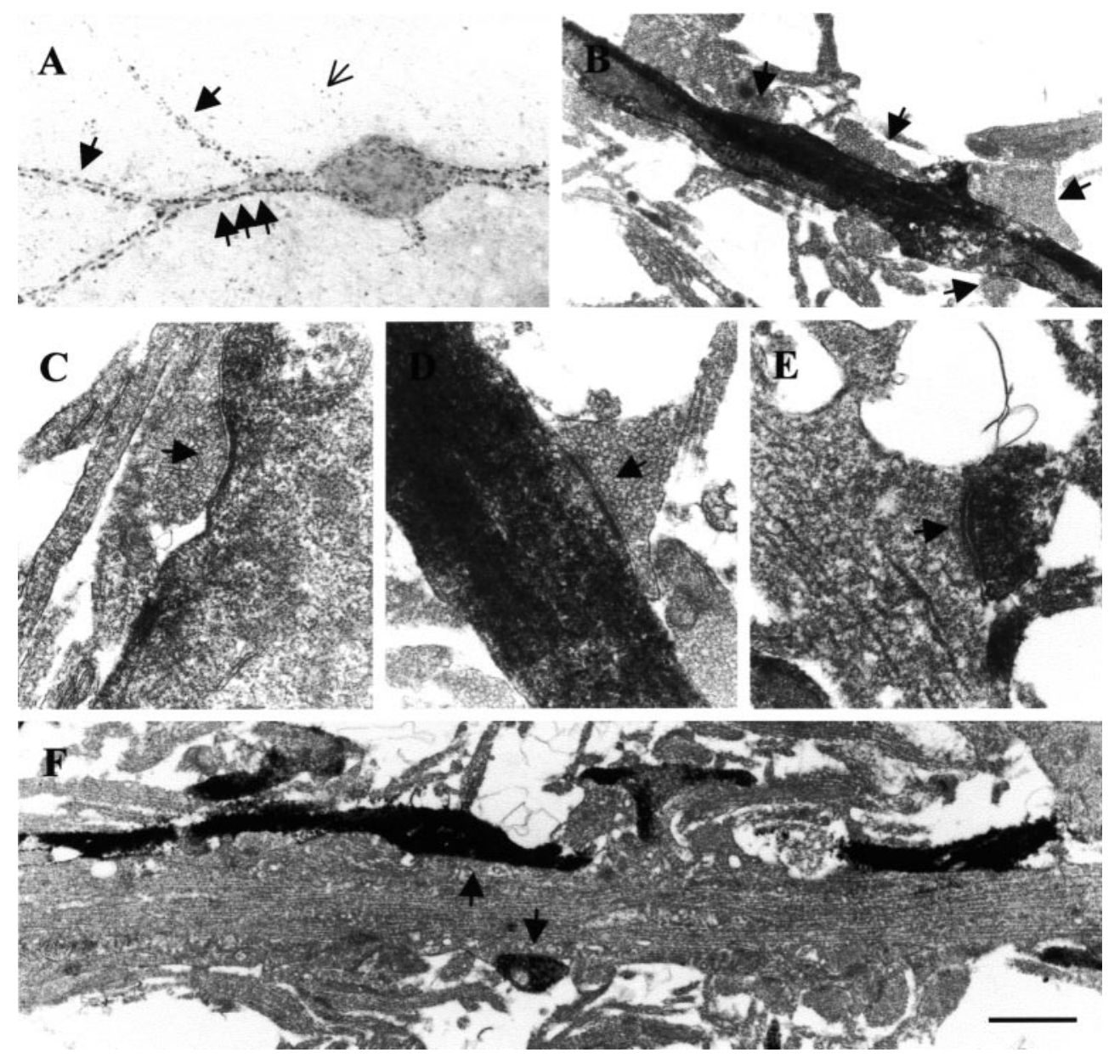

rons might be crucial for the initial generation of synchronous activity.

The morphological properties of the large GABAergic neurons suggest that these cells may be able to synchronize neuronal activity in the network by collecting randomly generated activity and distributing it throughout the network of developing neurons. Figure $5 B$ illustrates that GABAergic axons contact not only neurons in the proximity of their own cell body and dendritic field but also clusters of nerve cells placed far apart from it. We hypothesized that, being a collector that distributes incoming neuronal activity through the developing neuronal network, the large GABAergic neurons should participate in all synchronous events, and their activity should be predominantly at the onset of population $\left[\mathrm{Ca}^{2+}\right]_{\mathrm{i}}$ increase. To test this hypothesis, we recorded synchronous $\left[\mathrm{Ca}^{2+}\right]_{\mathrm{i}}$ oscillations in randomly chosen fields with higher temporal resolution. Afterward, GABAergic neurons were identified with anti-GABA immunocytochemistry, and the kinetics of fluo-3 fluorescence in individual GABAergic neurons were compared with those of the non-GABAergic neurons in the same field (Fig. $6 A, B$ ). From a total of 38 large GABAergic neurons recorded, all cells participated in all synchronous $\left[\mathrm{Ca}^{2+}\right]_{\mathrm{i}}$ changes occurring during the recording time. Analysis of the onset of $\left[\mathrm{Ca}^{2+}\right]_{\mathrm{i}}$ increase measured in individual neurons in relation to the onset of the synchronous event (defined as $\left[\mathrm{Ca}^{2+}\right]_{\mathrm{i}}$ increase in $>10$ neurons) revealed that $68 \%$ of the large GABAergic neurons became active before or within the first $100 \mathrm{msec}$ of the onset of the population event, whereas most $(69 \%)$ of non-GABAergic neurons responded after the first $100 \mathrm{msec}$ (Fig. 6C,D).

\section{Large GABAergic neurons are capable of driving synchronous network activity in the absence of glutamatergic transmission}

Next we asked whether large GABAergic neurons are capable of generating synchronous activity in the absence of the strong glutamatergic inputs converging onto their soma and dendrites and whether the output of these neurons could drive the developing glutamatergic neurons they innervate. To address this question, neuronal networks mitotically inhibited at 2 DIV were raised in the presence of the glutamate receptor antagonists $\mathrm{CNQX}$ and AP-V to prevent glutamatergic transmission during network development, whereas GABAergic transmission of the large GABA neurons was unaltered. Recordings of the changes in the neuronal $\left[\mathrm{Ca}^{2+}\right]_{i}$ at the end of the second week (13 DIV) showed that rhythmic synchronous neuronal activity had developed in the absence of glutamatergic transmission (Fig. 7A). The synchronous activity could be blocked by bicuculline (Fig. 7B), confirming GABA as the driving neurotransmitter. This result indicates that the large GABAergic neurons can drive most non-GABAergic neurons, which leads to a synchronous increase of $\left[\mathrm{Ca}^{2+}\right]_{\mathrm{i}}$ in these cells.

\section{Identification of large GABAergic neurons in the intact brain}

BrdU pulse label studies indicate that most of the cultured nerve cells dissociated from E16 rat cerebral cortex divide at least once in the culture dish (de Lima and Voigt, 1997, 1999) and thus are predominantly neurons destined for the future cortical plate 


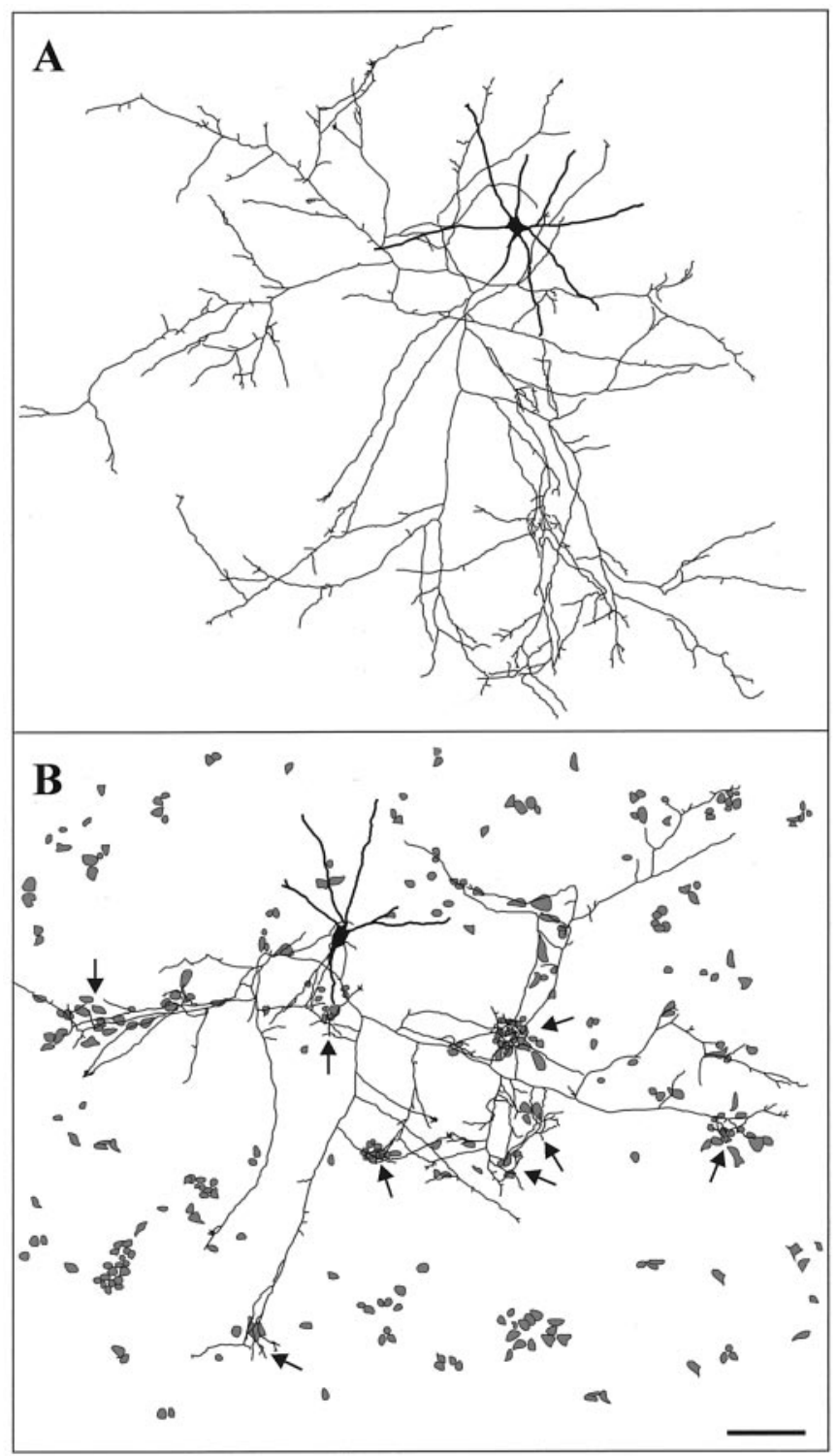

Figure 5. Widespread axonal coverage of large GABAergic neurons. A, Camera lucida drawing of a large GABAergic neuron. Dendrites are drawn as thick lines; the axon is depicted by the thin line. The axonal field of this neuron covers an area of $0.65 \mathrm{~mm}^{2} . B$, Camera lucida drawing of another large GABAergic neuron. Gray spheres depict somata of all other (nonGABAergic) neurons in the field. Arrows point to clusters of neurons that are intensely contacted by the GABAergic axon. Scale bar, $100 \mu \mathrm{m}$.

(Berry et al., 1964; Miller, 1985). A few of the neurons are postmitotic at the time of dissociation, among them the large GABAergic cells, which can be immunocytochemically identified just after attachment to the culture substrate (de Lima and Voigt, 1997). Consequently, these neurons should be present and identifiable in E16 embryos and should undergo mitosis at an earlier date. To determine the birth date of this unique cell type in situ, we labeled dividing cells within the embryos by applying the DNA marker BrdU to pregnant rats at E12, E13, E14, E15, or E16. Cell cultures were prepared from these embryos at E16, and the percentage of BrdU-positive GABAergic neurons was determined at 2 DIV (before the generation of small GABAergic neurons). These GABA-BrdU double-labeling experiments showed that the large GABAergic cells were born in the embryonic cortex between E12 and E15, with a peak of $>70 \%$ of BrdUlabeled large GABAergic neurons at E13 (Fig. $8 A$ ). Pulses of BrdU applied to E12 embryos labeled $>60 \%$ of the large GABAergic neurons in culture. Already at E15, a BrdU pulse resulted in $<15 \%$ of double-labeled large GABAergic neurons. Although BrdU application to E16 embryos resulted in a large number of BrdUmarked cells, none of the large GABAergic neurons was stained. This indicates that these neurons are postmitotic at E16, a time point when the lower portion of the cortical plate had just begun to form (Miller, 1985; Bayer and Altman, 1990; Ignacio et al., 1995; Valverde et al., 1995).

To complement the birth-dating study, the distributions of GABAergic neurons at E16 (when neurons were dissociated) and at P0 (when synchronous synaptic activity has been demonstrated in slices; Garaschuk et al., 2000) were determined. At E16, most GABAergic neurons were found in the lower intermediate and marginal zones, with a few GABAergic neurons scattered throughout the ventricular and subplate zones (Fig. 8B). The young cortical plate was virtually free of GABA cells. At birth (P0), GABAergic neurons were distributed in the marginal zone, deeper cortical plate, and subplate. The intermediate and ventricular zones contained only a few GABAergic neurons. These results are well in accordance with previous literature (Van Eden et al., 1989; Cobas et al., 1991) and show the conspicuous presence of GABAergic neurons in the early cortical network.

Next we tried to find out whether large GABAergic cells in culture could be identified as marginal zone or subplate neurons. With a birth-dating study, we tried to determine in the intact neonatal brain at P0 the position of GABAergic neurons generated at E12 or E14. Dividing cells were labeled by incorporation of BrdU for $12 \mathrm{hr}$ in E12 or E14 embryos, and brain sections were analyzed at birth. BrdU injection at E12 labeled cells in the subplate zone and to a lesser extend in the marginal zone. Double-labeled neurons that were stained for GABA and BrdU were found almost exclusively in the subplate (Fig. 8C). From 100 randomly inspected GABA neurons in the subplate zone, 43 were double-labeled, whereas in the directly adjacent portion of the lower cortical plate and the upper intermediate zone, only 2 and 3 of 100 GABA neurons, respectively, contained the mitotic marker. All other cortical layers contained no double-labeled neurons. The marginal zone was especially free of double-labeled GABAergic neurons at this early injection time. The same result, although with a slightly broadened profile across layers, was obtained when embryos were treated with BrdU at E14. In this case, 1 of 100 GABAergic marginal zone neurons, 11 of 100 lower cortical plate neurons, 47 of 100 subplate zone neurons, and 8 of 100 intermediate zone cells were double-labeled.

As an additional attempt to characterize the large GABAergic neurons, we used the low-affinity p75 nerve growth factor receptor that is expressed during cortical development in many neurons of the subplate (Allendoerfer et al., 1990; Koh and Higgins, 1991; Kordower and Mufson, 1992; Meinecke and Rakic, 1993; Chen et al., 1996; Mackarehtschian et al., 1999). To see whether the large GABAergic neurons were among the population of cells that expressed p75, we stained cell cultures obtained from E16 embryos at $4 \mathrm{hr}$, and 2, 7, and 14 DIV with anti-p75 antibodies. Regardless of the cultivation time, in none of the cultures investigated was there any detectable amount of p75 staining. As a control, we stained rat brains at E16 and P0. Although specific p75 immunoreactivity could not be detected in E16 cerebral cortex at significant levels, clear immunoreactive neurons were found in the intermediate and subplate zones of $\mathrm{P} 0$ cortices. This 
Figure 6. Large GABAergic neurons are active at the onset of each synchronous oscillatory event. $A$, Fluorometric $\mathrm{Ca}^{2+}$ recordings of 66 cells in a field of $380 \times 380$ $\mu \mathrm{m}^{2}$. Inset, Onset of synchronous $\left[\mathrm{Ca}^{2+}\right]_{\mathrm{i}}$ elevation at higher time resolution. The arrows point to the trace of a large GABAergic neuron that was identified by subsequent immunocytochemistry. $B$, Phase-contrast micrograph of the recorded field after immunolabeling of GABA. The large GABAergic neuron in the center with its dendrites can clearly be identified. Scale bar, $50 \mu \mathrm{m}$. $C, D$, Histograms of the onset of the $\mathrm{Ca}^{2+}$ transient in large GABAergic $(C)$ and all other $(D)$ neurons in 21 different fields relative to the onset of the synchronous oscillatory population event. Zero on the $x$-axis is the time point defined as the onset of the synchronous oscillatory event [i.e., when $\geq 10$ neurons in each field ( $n=$ 21 fields) had significantly increased $\left.\left[\mathrm{Ca}^{2+}\right]_{\mathrm{i}}\right]$. The arrow marks the statistical median.

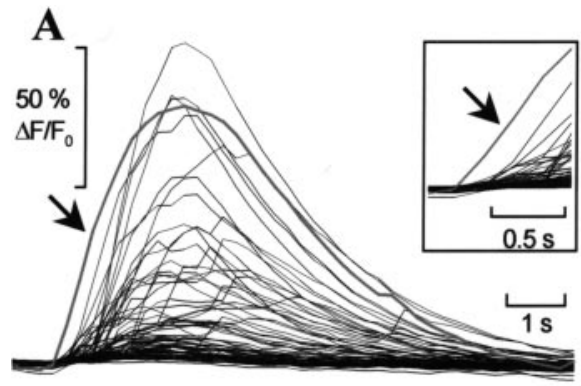

C
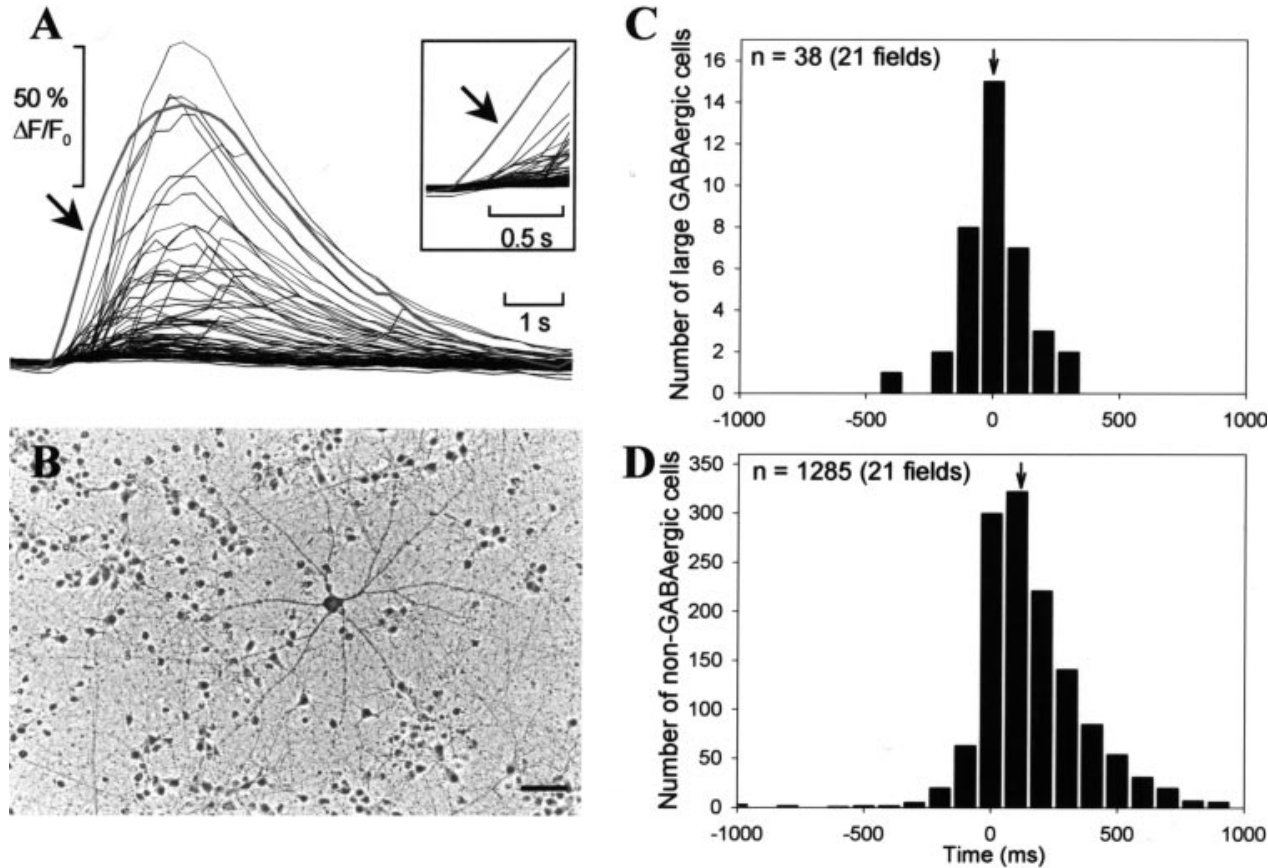

is in accordance with previous studies in rats showing that in the intact brain the expression of p75 in the cortical anlage is dramatically upregulated after E16 (Koh and Loy, 1989), with clear subplate labeling by E19 and during the first postnatal week (Koh and Higgins, 1991; Mackarehtschian et al., 1999). Accordingly, P75 immunoreactivity could not be detected in cultures taken from E16 rat brains $4 \mathrm{hr}$ after plating, a time point when large GABAergic neurons can be stained reliably for GABA (de Lima and Voigt, 1997).

Because early marginal zone GABAergic neurons may also express reelin (de Bergeyck et al., 1998; Meyer et al., 1998, 1999, 2000), we double stained cell cultures obtained from E16 embryos at $4 \mathrm{hr}$ and 2 and $7 \mathrm{DIV}$. Results showed that reelin is not expressed by large GABAergic neurons in vitro. Instead we found reelin expressed in a population of non-GABAergic nerve cells (Fig. 8D,E). This reinforces the result of BrdU-GABA double labeling in vivo, showing that the large GABAergic neurons in culture may not correspond to marginal zone neurons.

\section{DISCUSSION}

\section{GABA contribution to the generation of synchronized oscillatory calcium transients}

Slow network oscillations with exactly the same properties as found in culture (Murphy et al., 1992; Robinson et al., 1993; Voigt et al., 1997) have been described in slices of the hippocampus and cerebral cortex (Ben-Ari et al., 1989; Garaschuk et al., 1998, 2000). This network activity consists of intracellular $\mathrm{Ca}^{2+}$ transients that occur at a low rate of $0.5-6.0 / \mathrm{min}$, appear synchronously in almost the entire population of neurons, and exhibit a characteristic developmental profile, being present at birth and disappearing with further maturation during the second postnatal week (Khazipov et al., 1997; Leinekugel et al., 1997; Garaschuk et al., 1998, 2000). As in hippocampal slices (Garaschuk et al., 1998), synchronized calcium transients in cortical cultures are TTX-sensitive (Voigt et al., 1997) and are blocked either by the $\mathrm{GABA}_{\mathrm{A}}$ receptor antagonist bicuculline or by the NMDA and AMPA receptor antagonists AP-V and CNQX. Although ini- tially $\mathrm{GABA}_{\mathrm{A}}$ receptor antagonists block synchronous oscillatory activity completely, they fail to do so in more mature networks but reduce the frequency of synchronous events (T. Opitz, A. D. de Lima, and T. Voigt, unpublished results). The failure of $\mathrm{GABA}_{\mathrm{A}}$ receptor antagonists to block this activity completely in older networks may be caused by an increase in the efficacy of glutamatergic synaptic transmission rather than an alteration in the effect of GABA on the membrane potential. This view is supported by the fact that during the developmental period in question, the number of synapses increases dramatically (de Lima et al., 1997), whereas at the same time, GABA persists to act depolarizing (Owens et al., 1996). In slices of postnatal rat cerebral cortex, bicuculline failed to block the synchronous activity but reduced the frequency of the oscillatory events (Garaschuk et al., 2000). This behavior is consistent with the observed results in older cortical cultures and indicates that the GABA-sensitive period ends in the intact cortex before birth. The difference in bicuculline sensitivity observed between hippocampus and cortex (Garaschuk et al., 2000) is thus likely the result from different developmental time frames of both structures rather than from fundamentally different cellular mechanisms.

Studies in culture suggested that cooperative interactions between GABAergic and glutamatergic cells are involved in the generation of synchronized activity in neocortex (Murphy et al., 1992; Robinson et al., 1993; Maeda et al., 1995). Because no pacemaker potentials have been found to be associated with synchronous activity (Robinson et al., 1993), the occurrence of pacemaker cells is unlikely. However, different sets of data point to the importance of specific or even minority populations in the generation of synchronized activity. In the hypothalamus, for example, Misgeld et al. (1998) reported that $<5 \%$ of cultured neurons direct rhythmic firing of the general population. In slices of adult hippocampus, Cobb et al. (1995) showed that one type of GABAergic neuron can synchronize spontaneous firing activity of pyramidal cells. In layer 1 of the developing cerebral cortex, Schwartz et al. (1998) suggested that Cajal-Retzius cells controlled the correlated activity of non-Cajal-Retzius cells. 


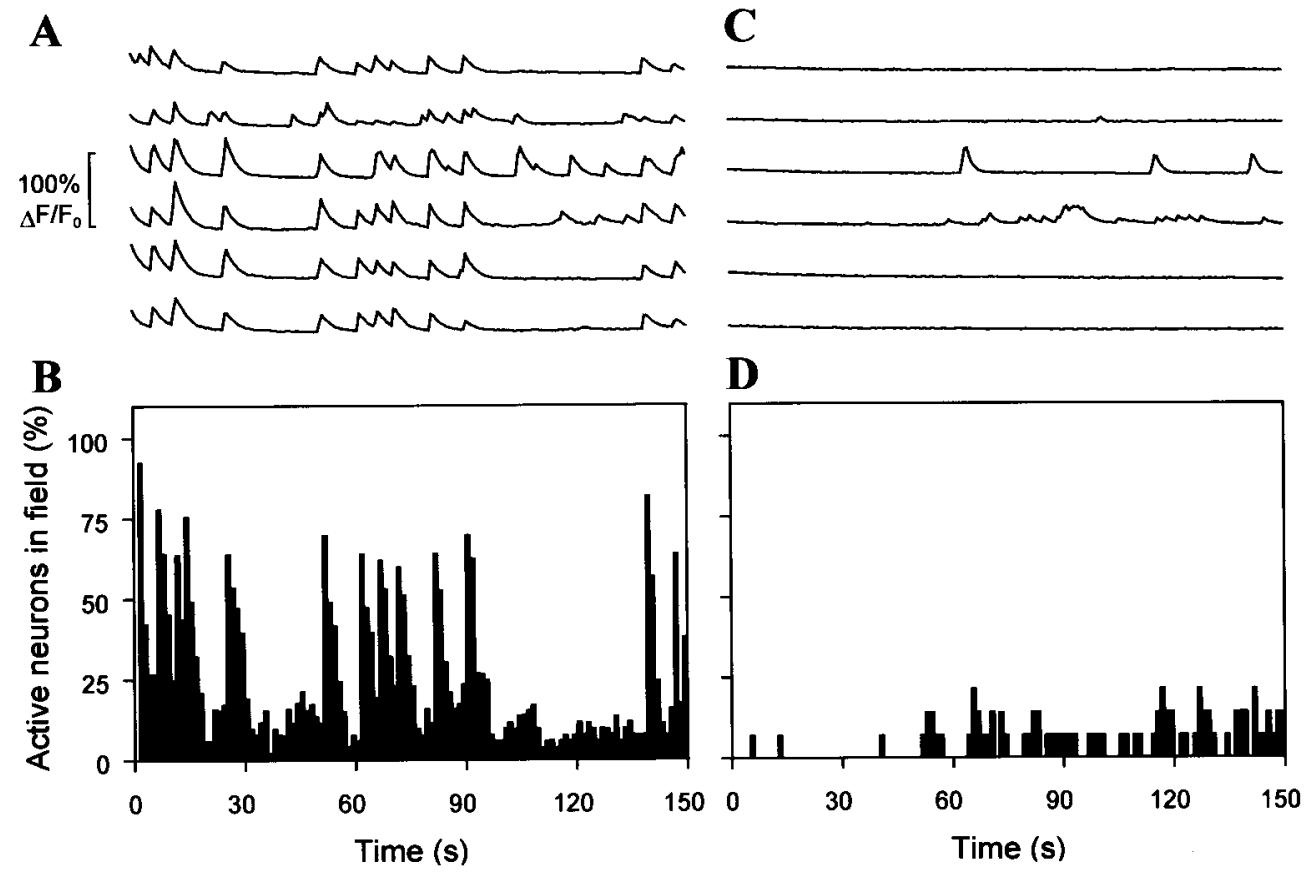

Figure 7. Large GABAergic neurons are capable of mediating synchronous $\left[\mathrm{Ca}^{2+}\right]_{\mathrm{i}}$ oscillations in cultured cortical neurons under blocked glutamatergic transmission. $A$, Fluorometric $\mathrm{Ca}^{2+}$ recordings of six representative neurons from a culture that was raised and recorded in the presence of ionotropic glutamate receptor blockers $(10 \mu \mathrm{M}$ CNQX and $50 \mu \mathrm{M}$ AP-V). A mitotic inhibitor was applied on the second DIV, thus suppressing the generation of small GABAergic neurons. $B$, Activity histogram of all the 54 neurons in the recorded field. $C$, Fluorometric $\mathrm{Ca}^{2+}$ recordings of the same six neurons as in $A$ after application of $20 \mu \mathrm{M}$ bicuculline. $D$, Activity histogram of all neurons in the recorded field after application of 20 $\mu \mathrm{M}$ bicuculline.
In this study we show that in culture, the large GABAergic neuron develops many features of neocortical basket cells (de Lima and Voigt, 1997), including the widespread axonal arborizations that target proximal sites of postsynaptic neurons and the characteristic high density of excitatory inputs on the dendritic shafts and their somata. The occurrence of synchronous activity is at least during the early phase of synaptogenesis dependent on the presence of this neuronal cell type. Our calcium-imaging data analyzing the $\left[\mathrm{Ca}^{2+}\right]_{\mathrm{i}}$ of identified large GABAergic neurons in comparison with the surrounding neuronal network show the leading role of these cells during the onset of the synchronized calcium events. Taken together, the physiological and morphological features of large GABAergic cells strongly suggest that this cell type acts as a collector and distributor of randomly generated activity, contributing decisively to the appearance of synchronous activity in cortical networks. Our data provide additional evidence that even in the absence of glutamatergic transmission, GABAergic neurons may be able to generate synchronous activity in the network, probably by upregulating the efficacy of GABAergic transmission.

\section{Identity of large GABAergic neurons}

The combination of GABA immunocytochemistry with the application of $12 \mathrm{hr}$ BrdU pulses at different gestational time points allowed us to determine the period during which the large GABAergic neurons detected in cell culture perform their final mitosis in the intact embryo. Most large GABAergic neurons become postmitotic between E12 and E15, a time point when the neurons of the primordial plexiform layer are generated (Miller, 1985; Bayer and Altman, 1990; Ignacio et al., 1995; Valverde et al., 1995). At E16, when the large GABAergic neurons are postmitotic, GABAergic neurons reside in vivo in the marginal zone (future layer 1) and in the intermediate zone (future white matter), with few neurons present in the subplate and ventricular zone (this study; Van Eden et al., 1989; Cobas et al., 1991). Between E16 and birth, the population of GABAergic neurons in the intermediate zone diminishes dramatically, and most GABAergic neurons are instead present in the subplate, cortical plate, and marginal zone. Recent evidence emphasizes the migration of neurons in the in- termediate zone and provides a possible explanation for the transitory nature of GABAergic neurons in the prenatal intermediate zone (DeDiego et al., 1994; Anderson et al., 1997, 1999). Thus, at least part of the GABAergic neurons that reside at birth and postnatally in the subplate and cortical plate may originate in the ganglionic eminence and reach their positions through tangential migration along the lower intermediate zone (DeDiego et al., 1994; del Rio et al., 2000; Parnavelas, 2000).

In the present study, we considered especially the location of early generated (E12-E14) GABAergic neurons at birth. Because synchronous activity depends on synaptic activity, it develops in vitro coincident with active synaptogenesis after at least 1 week of cultivation time (Voigt et al., 1997). This corresponds approximately to the time of birth in the intact animal. Accordingly, synchronous network activity is present during the first days after birth, a time of active synaptogenesis in the cortical plate (Blue and Parnavelas, 1983; Garaschuk et al., 2000). We found that most early GABAergic neurons were located in the subplate region at birth and concluded that these are in vivo correlates of the large GABAergic neurons characterized in vitro. Because a minor fraction of GABAergic neurons generated at E14 were also located in deep cortical layers, we cannot exclude the possibility that at least some of these later-born GABAergic neurons might turn out to be cortical plate neurons (Miller, 1985; Bayer and Altman, 1990; Ignacio et al., 1995; Valverde et al., 1995). Additional experiments showed that large GABAergic neurons in vitro are not reelin-positive, indicating that these cells are not a correlate of Cajal-Retzius neurons in the marginal zone. Because the marginal zone (layer 1) is target of neurons generated during the whole neurogenetic period (Fairén et al., 1986), it is feasible that the GABAergic neurons present at birth in this layer are generated later than the earliest primordial plexiform layer cohorts. Concerning the identification of the large GABAergic neurons as subplate neurons, it would be very desirable to be able to label these neurons in vitro with a marker specific for subplate neurons (Allendoerfer et al., 1990; Wahle et al., 1994; Landry et al., 1998). Unfortunately, markers such as subplate-1, low-affinity p75 nerve 

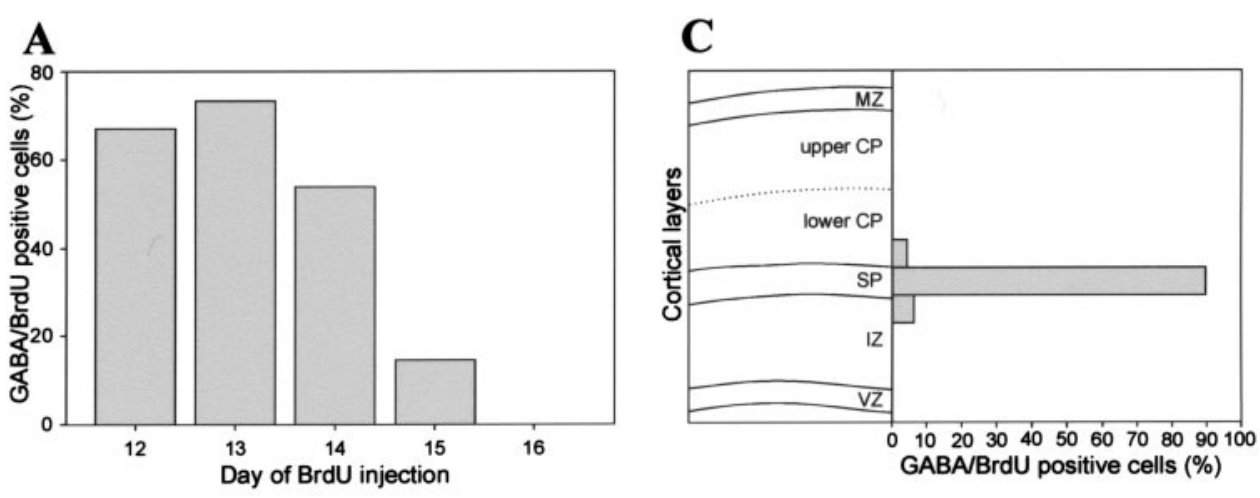

Figure 8. Birth date and localization of large GABAergic neurons in vivo. A, GABA and BrdU double-immunolabeled neurons in 2 DIV cultures raised from E16 embryos as percentage of all GABAergic neurons. The $x$-axis shows the embryonic day when the BrdU pulse was applied in vivo. $B$, Frontal section of rat cerebral cortex at E16 immunolabeled for GABA. The different layers are indicated on the right: $M Z$, Marginal zone; $C P$, cortical plate; $S P$, subplate; $I Z$, intermediate zone; $V Z$, ventricular zone. Scale bar, $50 \mu \mathrm{m}$. $C$, Distribution of GABA and BrdU double-immunolabeled neurons across the layers in a newborn rat. A BrdU pulse was administered at E12. Abbreviations of cortical layers are as in $B . D, E$, Same field in a 7 DIV culture double-labeled for GABA $(D$; secondary antibody, Cy3) and reelin (E; secondary antibody, Cy2). GABA and reelin are located in two different neurons. Arrows point to the reelin-positive neuron. Scale bar, $10 \mu \mathrm{m}$.
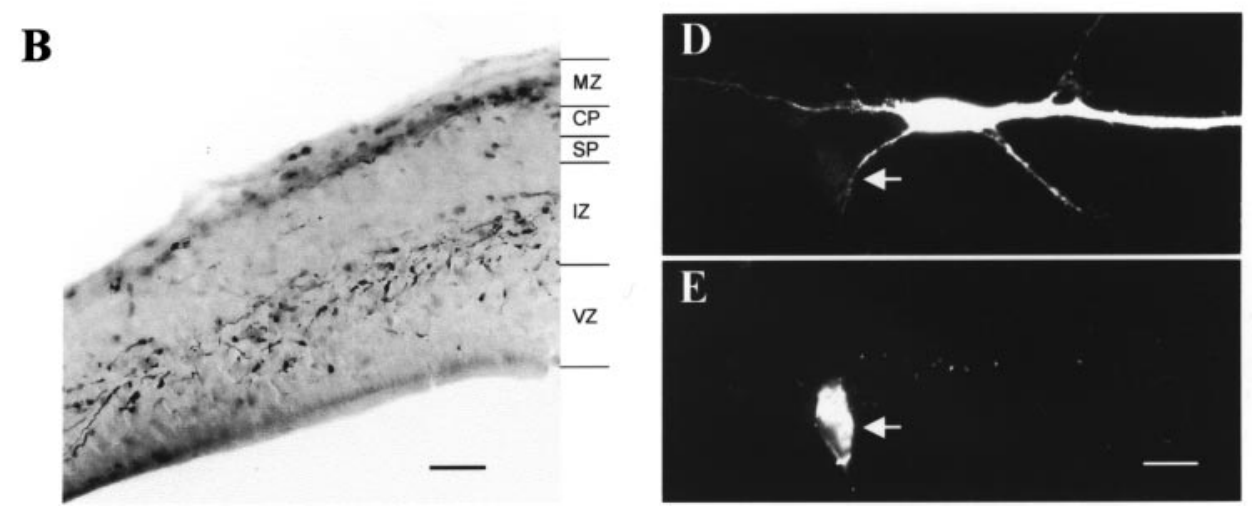

growth factor receptor, and golli proteins are transient in their expression in the subplate region and may depend critically on the influence of extrinsic afferences (Koh and Loy, 1989; Wahle et al., 1994). Additionally, although undoubtedly useful as cytoarchitectonic markers, they may not label all neuronal elements in the subplate, a necessary characteristic to make them useful as cellular markers (Meinecke and Rakic, 1993; Wahle et al., 1994). In the monkey, for example, p75 did not label an ultrastructurally distinct subpopulation of neurons (Meinecke and Rakic, 1993). Considering these facts, our failure to label early prenatal rat cortices or neurons growing in vitro with an antibody directed against p75 was predictable and may not invalidate the interpretation of the birth dating and GABA double-labeling experiments.

In summary, we conclude that most neurons developing in culture to large GABAergic neurons are derived from the primordial plexiform layer. On the basis of the double labeling with GABA and BrdU at birth, we hypothesize that large GABAergic neurons in vitro correspond to GABAergic cells that reside predominantly in the subplate at birth. Classic Golgi studies showed that early nonpyramidal neurons (putative GABAergic neurons) with long ascending axons (Martinotti cells and similar types) are quite common in the deep young rodent cortex, some of them clearly having basket-like axonal morphological features (Valverde, 1976; Fairén et al., 1984). The axons of these neurons show local arborization and reach with long branches the marginal zone, where they innervate with horizontally directed ramifications the apical dendrites of developing pyramidal cells (Marin-Padilla, 1984). These morphological features, which are astonishingly similar to the features of large GABAergic neurons developing in culture, put these neurons in the position to distribute activity in the local networks of the subplate and early differentiating cortical layers. In addition, with the horizontal ramification in the marginal zone, these neurons can innervate all future cortical neurons that reach this structure obligatorily with their leading processes, the future apical dendrites, when they terminate cell migration. Given the massive synaptic innervation large GABAergic neurons receive in culture, it is tempting to speculate that their in vivo correlates might also be targets for ingrowing axons. By contacting the elements that are responsible for the distribution of early cortical synchronous activity, the ingrowing axons would gain access to the developing cortical plate long before they invade this structure, and synchronization between subcortical and cortical activity as well as between cortical areas could be established. Alternatively, the correlates of large GABAergic neurons could form a horizontally connected network in the subplate region while the vertical output to the cortical plate is transmitted by glutamatergic neurons.

Finally, independent of their exact position in the primordial anlage in vivo, we hypothesize that early GABAergic neurons are a relatively homogenous population of basket-like neurons essential for the synchronization of neuronal activity during the development of the cerebral cortex.

\section{REFERENCES}

Allendoerfer KL, Shelton DL, Shooter EM, Shatz CJ (1990) Nerve growth factor receptor immunoreactivity is transiently associated with the subplate neurons of the mammalian cerebral cortex. Proc Natl Acad Sci USA 87:187-190.

Anderson S, Mione M, Yun K, Rubenstein JL (1999) Differential origins of neocortical projection and local circuit neurons: role of Dlx genes in neocortical interneuronogenesis. Cereb Cortex 9:646-654.

Anderson SA, Eisenstat DD, Shi L, Rubenstein JL (1997) Interneuron migration from basal forebrain to neocortex: dependence on Dlx genes. Science 278:474-476.

Bayer SA, Altman J (1990) Development of layer I and the subplate in the rat neocortex. Exp Neurol 107:48-62.

Ben-Ari Y, Cherubini E, Corradetti R, Gaiarsa JL (1989) Giant synaptic potentials in immature rat CA3 hippocampal neurones. J Physiol (Lond) 416:303-325.

Berry M, Rogers W, Eayrs JT (1964) Pattern of cell migration during cortical histogenesis. Nature 203:591-593.

Blue ME, Parnavelas JG (1983) The formation and maturation of syn- 
apses in the visual cortex of the rat. II. Quantitative analysis. J Neurocytol 12:697-712.

Chen EY, Mufson EJ, Kordower JH (1996) TRK and p75 neurotrophin receptor systems in the developing human brain. J Comp Neurol 369:591-618

Cobas A, Fairén A, Alvarez-Bolado G, Sánchez MP (1991) Prenatal development of the intrinsic neurons of the rat neocortex: a comparative study of the distribution of GABA-immunoreactive cells and the $\mathrm{GABA}_{\mathrm{A}}$ receptor. Neuroscience 40:375-397.

Cobb SR, Buhl EH, Halasy K, Paulsen O, Somogyi P (1995) Synchronization of neuronal activity in hippocampus by individual GABAergic interneurons. Nature 378:75-78.

de Bergeyck V, Naerhuyzen B, Goffinet AM, Lambert de Rouvroit C (1998) A panel of monoclonal antibodies against reelin, the extracellular matrix protein defective in reeler mutant mice. J Neurosci Methods 82:17-24.

DeDiego I, Smith-Fernandez A, Fairén A (1994) Cortical cells that migrate beyond area boundaries: characterization of an early neuronal population in the lower intermediate zone of prenatal rats. Eur J Neurosci 6:983-997.

de Lima AD, Voigt T (1997) Identification of two distinct populations of GABAergic neurons in cultures of the rat cerebral cortex. J Comp Neurol 388:526-541.

de Lima AD, Voigt T (1999) Astroglia inhibit the proliferation of neocortical cells and prevent the generation of small GABAergic neurons in vitro. Eur J Neurosci 11:3845-3856.

de Lima AD, Merten MDP, Voigt T (1997) Neuritic differentiation and synaptogenesis in neuronal cultures of the rat cerebral cortex. J Comp Neurol 382:230-246.

del Rio JA, Martinez A, Auladell C, Soriano E (2000) Developmental history of the subplate and developing white matter in the murine neocortex. Neuronal organization and relationship with the main afferent systems at embryonic and perinatal stages. Cereb Cortex 10:784-801.

Fairén A, DeFelipe J, Regidor J (1984) Nonpyramidal neurons. General account. In: Cerebral cortex, Vol 1, Cellular components of the cerebral cortex (Peters A, Jones EG, eds), pp 201-253. New York: Plenum.

Fairén A, Cobas A, Fonseca M (1986) Times of generation of glutamic acid decarboxylase immunoreactive neurons in mouse somatosensory cortex. J Comp Neurol 251:67-83.

Galli L, Maffei L (1988) Spontaneous impulse activity of rat retinal ganglion cells in prenatal life. Science 242:90-91.

Garaschuk O, Hanse E, Konnerth A (1998) Developmental profile and synaptic origin of early network oscillations in the CA1 region of rat neonatal hippocampus. J Physiol (Lond) 507:219-236.

Garaschuk O, Linn J, Eilers J, Konnerth A (2000) Large-scale oscillatory calcium waves in the immature cortex. Nat Neurosci 3:452-459.

Ignacio MPD, Kimm EJ, Kageyama GH, Yu J, Robertson RT (1995) Postnatal migration of neurons and formation of laminae in rat cerebral cortex. Anat Embryol (Berl) 191:89-100.

Isaac JT, Crair MC, Nicoll RA, Malenka RC (1997) Silent synapses during development of thalamocortical inputs. Neuron 18:269-280.

Juraska JM, Fifkova E (1979) An electron microscope study of the early postnatal development of the visual cortex of the hooded rat. J Comp Neurol 183:257-267.

Katz LC, Shatz CJ (1996) Synaptic activity and the construction of cortical circuits. Science 274:1133-1138.

Khazipov R, Leinekugel X, Khalilov I, Gaiarsa JL, Ben-Ari Y (1997) Synchronization of GABAergic interneuronal network in CA3 subfield of neonatal rat hippocampal slices. J Physiol (Lond) 498:763-772.

Koh S, Higgins GA (1991) Differential regulation of the low-affinity nerve growth factor receptor during postnatal development of the rat brain. J Comp Neurol 313:494-508.

Koh S, Loy R (1989) Localization and development of nerve growth factor-sensitive rat basal forebrain neurons and their afferent projections to hippocampus and neocortex. J Neurosci 9:2999-3018.

Kordower JH, Mufson EJ (1992) Nerve growth factor receptorimmunoreactive neurons within the developing human cortex. J Comp Neurol 323:25-41.

Kristt DA (1978) Neuronal differentiation in somatosensory cortex of the rat. I. relationship to synaptogenesis in the first postnatal week. Brain Res 150:467-486.

Kyrozis A, Reichling DB (1995) Perforated-patch recording with gramicidin avoids artifactual changes in intracellular chloride concentration. J Neurosci Methods 57:27-35.

Landry CF, Pribyl TM, Ellison JA, Givogri MI, Kampf K, Campagnoni CW, Campagnoni AT (1998) Embryonic expression of the myelin basic protein gene: identification of a promoter region that targets transgene expression to pioneer neurons. J Neurosci 18:7315-7327.

Leinekugel X, Medina I, Khalilov I, Ben-Ari Y, Khazipov R (1997) $\mathrm{Ca}^{2+}$ oscillations mediated by the synergistic excitatory actions of $\mathrm{GABA}_{\mathrm{A}}$ and NMDA receptors in the neonatal hippocampus. Neuron 18:243-255.

Mackarehtschian K, Lau CK, Caras I, McConnell SK (1999) Regional differences in the developing cerebral cortex revealed by ephrin-A5 expression. Cereb Cortex 9:601-610.

Maeda E, Robinson HPC, Kawana A (1995) The mechanisms of generation and propagation of synchronized bursting in developing networks of cortical neurons. J Neurosci 15:6834-6845.

Marin-Padilla M (1984) Neurons of layer 1. A developmental analysis. In: Cerebral cortex, Vol 1, Cellular components of the cerebral cortex (Peters A, Jones EG, eds), pp 447-478. New York: Plenum.

Meinecke DL, Rakic P (1993) Low-affinity p75 nerve growth factor receptor expression in the embryonic monkey telencephalon: timing and localization in diverse cellular elements. Neuroscience 54:105-116.

Meister M, Wong ROL, Baylor DA, Shatz CJ (1991) Synchronous bursts of action potentials in ganglion cells of the developing mammalian retina. Science 252:939-943.

Meyer G, Soria JM, Martinez-Galan JR, Martin-Clemente B, Fairén A (1998) Different origins and developmental histories of transient neurons in the marginal zone of the fetal and neonatal rat cortex. J Comp Neurol 397:493-518.

Meyer G, Goffinet AM, Fairén A (1999) What is a Cajal-Retzius cell? A reassessment of a classical cell type based on recent observations in the developing neocortex. Cereb Cortex 9:765-775.

Meyer G, Schaaps JP, Moreau L, Goffinet AM (2000) Embryonic and early fetal development of the human neocortex. J Neurosci 20:1858-1868.

Miller MW (1985) Cogeneration of retrogradely labeled corticocortical projection and GABA-immunoreactive local circuit neurons in cerebral cortex. Dev Brain Res 23:187-192.

Misgeld U, Zeilhofer HU, Swandulla D (1998) Synaptic modulation of oscillatory activity of hypothalamic neuronal networks in vitro. Cell Mol Neurobiol 18:29-43.

Murphy TH, Blatter LA, Wier WG, Baraban JM (1992) Spontaneous synchronous synaptic calcium transients in cultured cortical neurons. J Neurosci 12:4834-4845.

O'Donovan MJ (1999) The origin of spontaneous activity in developing networks of the vertebrate nervous system. Curr Opin Neurobiol 9:94-104

Owens DF, Boyce LH, Davis MBE, Kriegstein AR (1996) Excitatory GABA responses in embryonic and neonatal cortical slices demonstrated by gramicidin perforated-patch recordings and calcium imaging. J Neurosci 16:6414-6423.

Owens DF, Liu X, Kriegstein AR (1999) Changing properties of $\mathrm{GABA}_{\mathrm{A}}$ receptor-mediated signaling during early neocortical development. J Neurophysiol 82:570-583.

Parnavelas JG (2000) The origin and migration of cortical neurones: new vistas. Trends Neurosci 23:126-131.

Peinado A (2000) Traveling slow waves of neural activity: A novel form of network activity in developing neocortex. J Neurosci 20:1-6.

Penn AA, Riquelme PA, Feller MB, Shatz CJ (1998) Competition in retinogeniculate patterning driven by spontaneous activity. Science 279:2108-2112.

Robinson HPC, Kawahara M, Jimbo Y, Torimitsu K, Kuroda Y, Kawana A (1993) Periodic synchronized bursting and intracellular calcium transients elicited by low magnesium in cultured cortical neurons. J Neurophysiol 70:1606-1616.

Schwartz TH, Rabinowitz D, Unni V, Kumar VS, Smetters DK, Tsiola A, Yuste R (1998) Networks of coactive neurons in developing layer 1. Neuron 20:541-552.

Shatz CJ (1990) Impulse activity and the patterning of connections during CNS development. Neuron 5:745-756.

Sretavan DW, Shatz CJ, Stryker MP (1988) Modification of retinal ganglion cell axon morphology by prenatal infusion of tetrodotoxin. $\mathrm{Na}$ ture 336:468-471.

Takahashi T, Nowakowski RS, Caviness Jr VS (1992) BUdR as an S-phase marker for quantitative studies of cytokinetic behaviour in the murine cerebral ventricular zone. J Neurocytol 21:185-197.

Valverde F (1976) Aspects of cortical organization related to the geometry of neurons with intracortical axons. J Neurocytol 5:509-529.

Valverde F, De Carlos JA, López-Mascaraque L (1995) Time of origin and early fate of preplate cells in the cerebral cortex of the rat. Cereb Cortex 5:483-493

Van Eden CG, Mrzljak L, Voorn P, Uylings HBM (1989) Prenatal development of GABA-ergic neurons in the neocortex of the rat. J Comp Neurol 289:213-227.

Voigt T, Baier H, de Lima AD (1997) Synchronization of calcium activity promotes survival of individual rat neocortical neurons in early development. Eur J Neurosci 9:990-999.

Wahle P, Lübke J, Naegele JR (1994) Inverted pyramidal neurons and interneurons in cat cortical subplate zone are labelled by monoclonal antibody SP1. Eur J Neurosci 6:1167-1178.

Wong ROL, Meister M, Shatz CJ (1993) Transient period of correlated bursting activity during development of the mammalian retina. Neuron 11:923-938

Wong ROL, Chernjavsky A, Smith SJ, Shatz CJ (1995) Early functional neural networks in the developing retina. Nature 374:716-718. 